\title{
Development of New Plant Growth Regulators from a University Perspective
}

\author{
Duane W. Greene
}

Additional IndeX words. plant bioregulants, PBRs, university-based research

Summary. Plant growth regulators (PGRs) play an important commercial role in horticulture. Although often expensive, they are generally used on high value crops where the costs can be retrieved through the increased value their usage creates in a given crop. The impetus for development of new PGRs is generally initiated by the agrochemical industry where they perceive a need that has a profit potential, whereas the motivation for the development of a PGR by researchers is largely to aid the industry they serve. University and government researchers initially follow a prescribed protocol early in the development process, but once they have gained personal experience with a PGR, further research is often guided by personal observations and keen technical insight. During the development and evaluation process, university and government researchers are optimistic, and negative effects are generally viewed as challenges, that can and will be overcome. Discussion and effective communication are critical components in the overall development of a new PGR. Researchers generally exchange information very freely, unless restricted from doing so by a nondisclosure or other contract agreement. The underlying goal for university and government researchers is to get approval of a new PGR product and/or use that will allow growers to produce a high quality product for consumers with an improved profit margin for growers. Development of new PGRs is undergoing major change that unfortunately will lead to the development and registration of fewer compounds. There are not as many agrochemical companies, there are a decreasing number of university and government researchers, and diminishing funds available to support the development of new PGRs.

$\mathrm{P}$ lant growth regulators play an important role in commercial horticulture, especially for the tree fruit industry. While they are often expensive, they are used on high value crops where the cost can be recovered, because of the higher value they create within the crop (Looney, 1993). Frequently, PGRs do not increase yield, or if they do, it is not the primary labeled benefit (Elfving and Allen, 1987; Taylor, 1978, Unrath, 1974). Most often the influence of a PGR is on improving fruit quality and increase consumer appeal (Looney, 1993). Since most researchers are commodity oriented, they are constantly looking for PGRinduced changes that may improve their crop and increase its value.

The impetus for the development of a new PGR comes from three sources.

1) Agrochemical industry. The large majority of new PGRs come from discovery or development by the agrochemical industry. Many of these came as the result of initial observations made in herbicide or fungicide trials. The number of companies developing new PGRs has now decreased dramatically, and not surprisingly, so has the number of compounds available for testing.

2) Agricultural commodity groups. There are a few examples where encouragement to develop a compound have come from the industry itself. The development of and registration of Accel (Valent BioSciences, Libertyville, Ill.) for thinning of apples (Malus $\times$ domestica), especially on Empire, is an example of this. We may have more of this type of industry involvement in the future, if companies are willing to partially subsidize development. The fruit industry is experiencing difficult financial times, thus money to support registration and research is limited. 
3) Universityand governmentresearchers. Researchers are not driven by a profit motive, but rather they aid development of compounds that can substantially aid the industry. Researchers did also provide some encouragement for the development of Accelasachemical thinner. Perhaps the bestexample of university prodding for compound development was the development and very recent registration of Apogee (BASF Corp., Research Triangle Park, N.C.). While there were a number of BASF employees who could see vividly the commercial value of such a compound, it took strong external support by researchers to persuade company executives of the need for Apogee and the potential for itscommercial success. A recently published workshop on Apogee at ASHS-1997 in Salt Lake City, Utah, was a direct result of researchinvolvementandencouragement in product development and registration (Byers and Yoder, 1999; Evans et al., 1999; Greene, 1999; Owens and Stover, 1999; Unrath, 1999; Yoder et al., 1999).

When a researcher receives a new or numbered compound from an agrochemical company there are a number of steps that are routinely taken in its evaluation and development.

Arrival and initial applicaTION. Generally before a compound is received by a researcher from an agrochemical company it has gone through in-house screening and was identified as having potentially useful effects. Usually a compound arrives with suggested rates, timings, and an evaluation protocol. Since researchers often have neither experience nor prior knowledge about the effects this compound has on their crop, these protocols are generally followed quite closely.

Observation. A critical component in the evaluation process is observation. The best and most successful researchers who really drive the development process are not only excellent scientists but are also hands-on in their approach and remain very much involved during the whole product evaluation process. Examples of observations that have lead to product development or expansion of PGR use include most recently the observation that inhibition of fire blight (Erwinia amylovora) by the growth retardant Apogee (Yoder, 2001), and examples cited in Miller (1989) and Looney (1983).
Application. There are a number of formulation problems that can surface during the application process that may affect the final result. Does the product foam excessively in the spray tank? Does the formulation dissolve completely or dissolve with difficulty. Does it precipitate in the spray tank? Does the compound clog the spray nozzles? Feed back regarding these types of problems is very useful for agrochemical companies, and it allows them to address the problem during the early stages of development.

Horticultural effects and PHyтотохісітY. Does the PGR elicit responses that are not necessarily part of the evaluation protocol? Examples include increased fruit set following application of Apogee (Greene, 1999), fruit thinning following Promalin (Valent BioSciences) application (Unrath, 1974), increased fruit russet from some blossom thinners (Byers, 1997), and leaf or fruit malformation. Are there phytotoxic effects such as burning, chlorosis, or necrosis?

Harvest and postharvest EVALUATION. If a PGR influences vegetative growth or crop load in any way during the growing season, the chances are very great that effects will be apparent and can be measured at harvest. A thorough evaluation is done at harvest and this normally includes measuring fruit size, shape, red color, firmness, soluble solids, maturity, and yield. Often times fruit flesh firmness, storage disorders, and the incidence of decay is evaluated after an appropriate period of storage. Further, monitoring carryover effects such as return bloom, growth retardation, and fruit effects should be routine since many PGRs do show carryover effects: daminozide (Southwick et al., 1973), ethephon (Williams, 1975), paclobutrtazol (Greene, 1986), and aminoethoxyvinylglycine (AVG) (Greene, 1983).

Evaluation and suggestions FOR IMPROVEMENT. In general, I believe that researchers are a very optimistic group. They want to see a compound succeed and ultimately receive full label registration. Researchers look at the positive attributes with great enthusiasm. Negative elements associated with the compound are considered temporary challenges or inconveniences. Rarely are faults considered so serious or troubling as to as to jeopardize further development of the compound. There are several things that researchers frequently do to overcome negative effects and improve product performance and they include: change in formulation, inclusion or use of a different surfactant, change in concentration, change in time of application, change in spray volume, method of application, or droplet size, and the use of split applications. It has been my observation that researchers have been somewhat creative and resourceful in manipulating conditions so that most negative effects can be minimized or even eliminated. In most cases the reason that commercial development of a highly effective PGR is terminated is not because of unfavorable field efficacy as determined by researchers, but rather difficulty in gaining product registration, or by the company due to unfavorable bottom line projections.

\section{Discussion}

Discussion and effective communication are critical components in the overall development of a new PGR. Not only is it vitally important to the project but everyone that I know of who is involved in PGR development really enjoys the interchange of ideas. Product development moves along much more rapidly when researchers get involved in open discussion with agrochemical company scientists. Somewhere along the line most of us encounter the contract nondisclosure dilemma. Confidentiality agreements are somewhat common in industry, and they are used by agrochemical companies to protect proprietary information. Many universities have very restrictive constraints associated with entering confidentiality agreements for a number of reasons. Young, nontenured faculty may find them unacceptable because of the need to publish to get tenure and promotions. While a nondisclosure commitment does limit public discussion, it does focus discussion with a limited number of interested people. My personal feeling is that I will sign one, because if I do not, I will not be allowed to participate in the development of a potentially important compound. Further, signing a confidentially agreement often times allows me to participate in discussions that I would not normally be privy to where new insights or in-house research are discussed. Looking back, I do not see that confidentially clauses have been either a great inconvenience or disadvantage to me as a researcher. 


\section{Northeast PGR Working Group}

One of the most useful associations I have professional affiliation with is the participation in this Northeast PGRWorking Group. It is a very loosely organized group that originated in the early 1970 s, specifically to aid interaction and exchange ideas to facilitate the development of PGRs in tree fruit. It is a public forum that now meets annually where industry, university, and government professionals openly and freely exchange data and ideas. At this meeting researchers and agrochemical company representatives present data and thoroughly discuss results in an informal setting. When the group feels that it is appropriate, research protocols are established which allows identical treatment to be evaluated in different locations and under widely differing environmental conditions. I credit this group for facilitating and speeding up PGR development (Promalin Accel, Apogee) because data is discussed, candid discussions occur, and suggestions for future work are discussed.

\section{Things have changed}

PGR evaluation has changed over the past quartercentury. There are fewer agrochemical companies developing PGRs, and not surprisingly fewer compounds available to evaluate. Money from state and federal sources to support development of new PGRs is essentially nonexistent. Research direction is more determined by available research dollars than perceived research need in a particular area. Now researchers are almost totally dependent upon grants in aid from agrochemical companies to support develop new PGRs. A limited amount of support comes from grower associations with funding mechanisms (e.g., Michigan, New York, Pennsylvania, Virginia, Washington, and other states) if the growers involved in allocating the funds perceive that development of a particular compound will be of direct benefit to them.

\section{Development of specific PGRs}

I have been involved in the development of a number of PGRs, many of which never made it to commercialization. Each compound presented its own unique set of challenges, although the development of each followed more or less the pattern just described. I have selected three PGRs to briefly illustrate the development process.

Paclobutrazol (PP-333, CultaR). Paclobutrazol (BASF Corp.) was the most difficult and perhaps the most challenging compound that most of us have encountered. It is a very effective growth retardant, but there were several side effects that caused major problems (Greene, 1986). First it increased fruit set, sometimes excessively, which resulted in heavy-set trees which produced small fruit. It was persistent in the soil and this could last for a number of years depending on soil type and the amount initially applied. Modifications included applying lower label rates, using foliar application, and delaying application until after initial fruit set, which minimized negative effects on fruit size. Its development was an excellent example of professional and commercial cooperation that ultimately overcame most difficulties associated with its use. Commercial use of the compound in tree fruit in the United States was terminated because of persistence in the soil and possible ground water contamination, both of which would make it difficult to receive registration. It is sold in other countries and in this country for use on nonedible landscape perennials.

ACcel. Accel had its beginning with the product Promalin, a mixture containing equal amounts (1.8\%) of gibberellin $\left(\mathrm{GA}_{4+7}\right)$ and benzyladenine (BA), that was developed primarily to elongate 'Red Delicious' apple fruit. It was known very early that Promalin could thin but recommendations for its use were made to minimize the thinning response. When the two compounds contained in Promalin were evaluated separately, both for fruit elongation and lateral branch development, it was found that BA could in fact thin and even defruit trees when used at high enough concentrations. In the early 1980s research data suggested that BA was a good candidate as a chemical thinner since it thinned, increased flower bud formation, and unique compared to other chemical thinners, it could also increase fruit size beyond that which could be attributed to a reduction in crop load. Researchers and the eastern apple industry were very anxious to have this product available because as a thinner and fruit size enhancer, BA looked extremely effective. Registration of BA by Abbott Laboratories (North Chicago, Ill.) was delayed for a number of years because of economic reasons, but when ultimately registered, it was submitted as an altered Promalin formulation with one tenth the amount of $\mathrm{GA}_{4+7}$.

ReTain (AVG). Development and registration of PGRs is not always rapid and ReTain (Valent BioSciences) is a good example of this. The time between when I first received a research sample of AVG from Hoffman La Roche (Nutley, N.J.) for evaluation on apples until it was registered spanned 19 years. Development of the compound was suspended by the original developer, and later by Maag Chemical Company (Vero Beach, Fla.) because of the high cost of production. There was a 10-year lapse of time during which no active commercial development of AVG occurred. In the late $1980 \mathrm{~s}$ the registration of daminozide for preharvest drop control and improved quality of apples was withdrawn. Abbott Laboratories recognized that AVG might be a compound that could fill the void left by the loss of daminozide (Bangerth, 1978; Bramlage et al., 1980; Williams, 1980). The first step was to confirm if AVG could effectively retard preharvest drop (Greene, 2000). Following this there were a series of experiments conducted over several years that established concentration, time of application, adjuvants, formulations, and other important factors which followed a logical sequence, and built upon one another. Of the compounds that I have worked with, the commercial development of AVG was one of the easiest and most efficient because of an excellent group of researchers supporting development, an excellent group of people at Abbott that brought the product along, and a cooperative compound.

In conclusion, PGRs do play an important role in commercial horticulture, especially in the tree fruit industry. The university and government researchers have played a positive and important role in developing PGRs for the benefit of both growers and consumers. The results are that growers are now producing a better quality and consistent crops and consumers are receiving a higher quality product. However, things are changing. There are fewer agrochemical companies that are testing fewer potential new PGRs 
and not as many researchers are available to evaluate them. University faculties are decreasing in size and when vacancies do appear, job descriptions are being rewritten to favor hiring individuals in the basic sciences or in biotechnology rather than commodity-oriented individuals. The future is unclear. Agrochemical companies may be forced to rely on internal resources and on contract research for product development. Alternatively, the agrochemical industry, commodity groups, and universities should discuss forging some type of partnership to see that this system that worked so effectively in the past may evolve into a smaller but equally effective system to develop new products.

\section{Literature cited}

Bangerth, F. 1978. Effect of substituted amino acids on ethylene biosynthesis respiration, ripening, and preharvest drop of apple fruits. J. Amer. Soc. Hort. Sci. 103:401-404.

Bramlage, W.J., D.W. Greene, W.R.Autio, and J.M. Mclaughlin. 1980. Effects of amionethoxyvinylglycine on internal ethylene concentrations and storage of apples. J. Amer. Soc. Hort. Sci. 105:847-851.

Byers, R.E. 1997. Effects of bloom-thinning chemicals on apple fruit set. J. Tree Fruit Prod. 2:13-31.

Byers, R.E. and K.S. Yoder. 1999. Prohexadione-calcium inhibits apple, but not peach tree growth, but has little influence on apple fruit thinning or quality. HortScience 334:1205-1209.
Elfving, D.C. and O.B. Allen. 1987. Effects of gibberellins $\mathrm{A}_{4+7}$ applications on 'Golden Delicious' fruit russet. Crop Res. 27:11-18.

Evans, J.R., R.R. Evans, C.L Regusci, and W. Rademacher. 1999. Mode of action, metabolism, and uptake of BAS $125 \mathrm{~W}$, prohexadione-Ca. HortScience 34:12001201.

Greene, D.W. 1983. Some effects of aminoethoxyvinylglycine on fruit set, fruit characteristics, and vegetative growth of apple trees. J. Amer. Soc. Hort. Sci. 108:410-415.

Greene,D.W. 1986. Effect of paclobutrazol and analogs on growth, yield, fruit quality, and storage potential of 'Delicious' apples. J. Amer. Soc. Hort. Sci. 111:328-332.

Greene, D.W. 1999. Tree growth management and fruit quality of apple trees treated with prohexadione-calcium (BAS 125). HortScience 34:1209-1212.

Greene, D.W. 2000. Development of amonoethoxyvinylglycine (AVG) to retard preharvest drop in apples. Acta Hort. 527:105-109.

Looney, N.E. 1983. Growth regulator usage in apple and pear production, p. I26. In: L.G. Nickell (ed.). Plant growth regulating chemicals. vol. 1. CRC Press, Boca Raton, Fla.

Looney, N.E. 1993. Improving fruit size, appearance, and other aspects of fruit crop "Quality" with plant bioregulating chemicals. Acta Hort. 329:120-126.

Miller, S.S. 1989. Plant bioregulators in apple and pear culture. Hort. Rev. 10:309402.
Owens, C.L. and E. Stover. 1999. Vegetative growth and flowering of young apple trees in response to prohexadione-Ca. HortScience 34:1194-1196.

Southwick, F.W., W.J. Lord, D.W. Greene, and L.G. Cromack. 1973. Residual effects of summer applications of succinic acid 2,2-dimethylhydrazide (Alar) on 'McIntosh' apple trees. J. Amer. Soc. Hort. Sci. 98:593-595.

Taylor, B.K. 1978. Effects of gibberellin sprays on fruit russet and tree performance of 'Golden Delicious' apple. J. Hort. Sci. 53:167-169.

Unrath, C.R. 1974. The commercial implications of gibberellin $\mathrm{A}_{4} \mathrm{~A}_{7}$ plus benzyladenine for improving shape and yield of 'Delicious' apples. J. Amer. Soc. Hort. Sci. 99:381-384.

Unrath, C.R. 1999. Prohexadione-Ca: A promising chemical for controlling vegetative growth of apples. HortScience 34:1197-1200.

Williams, M.W. 1975. Carry over effect of ethephon on fruit shape of 'Delicious' apples. HortScience 10:523-524.

Williams, M.W. 1980. Retention of fruit firmness and increase in vegetative growth and fruit set of apples with aminoethoxyvinylglycine. HortScience 15:76-77.

Yoder, K.S. 2001. Suppression of fire blight of apple shoots by Apogee. Compact Fruit Tree 34:50-53.

Yoder, K.S., S.S. Miller, and R.E. Byers. 1999. Suppression of fireblight in apple shoots by Prohexadione-calcium following experimental and natural inoculation. HortScience 34:1202-1204. 